\title{
La atribución de responsabilidad individual por el delito ambiental del art. 291 del Código Penal cometido en el seno de organizaciones empresariales*
}

\author{
Lautaro Contreras Chaimovich**
}

\begin{abstract}
RESUMEN
En este trabajo nos preguntamos acerca de cuáles son las reglas que permiten imputar una responsabilidad individual por el delito del art. 291 del Código Penal, cuando este se comete en ámbitos empresariales, y qué dificultades puede presentar la aplicación de aquellas. Luego de mostrar que dichas reglas son las propias de la intervención delictiva, y de exponer la forma en que estas permiten fundar la responsabilidad de personas que ocupan posiciones de subordinación, se revisan sus importantes limitaciones para sancionar a los órganos superiores de una empresa.
\end{abstract}

Delitos medioambientales - artículo 291 del Código Penal chileno - intervención delictiva en ámbitos empresariales

\section{Personal liability for the environmental crime of art. 291 of the Chilean Penal Code committed within enterprise organizations}

\begin{abstract}
In this paper we raise the question about which are the rules that allow the attribution of personal liability for the crime of Article 291 of the Chilean Penal Code when it is committed within corporate areas, and what difficulties may arise from the application of those rules. After showing that these rules are those of criminal intervention, and after exposing the way in which they make it possible to base the liability of persons who occupy subordinate positions, we review their important limitations to punish the higher organs of a company.
\end{abstract}

Environmental crimes - article 291 of the Chilean Penal Code - criminal intervention within the corporate field

* Este artículo corresponde sustancialmente a la investigación que sirvió de base para mi opinión científica expresada en un Informe en Derecho, en una causa penal que el solicitante ha preferido mantener en reserva, razón por la que se ha omitido toda referencia a los antecedentes de la misma.

** Licenciado en Ciencias Jurídicas y Sociales, Universidad de Chile. Doctor en Derecho, Universidad de Friburgo, Alemania. Profesor de Derecho Penal, Universidad de Chile. Correo electrónico: 1contreras@derecho.uchile.cl

Artículo recibido el 28.4.2020 y aceptado para su publicación el 29.7.2020. 


\section{INTRODUCCIÓN}

L a mejora de la protección del medio ambiente ha sido una prioridad para Chile en los últimos años. Para tal fin, el país ha fortalecido de manera significativa sus instituciones estatales y ha introducido instrumentos de gestión ambiental pioneros en América Latina. En materia de política criminal, Chile ha mostrado avances en la protección penal de la biodiversidad ${ }^{1}$, en el combate al tráfico ilícito de residuos peligrosos ${ }^{2}$, y en el castigo de los daños a ecosistemas causados por incendios ${ }^{3}$. Además, se ha reformado el delito de contaminación de aguas, incorporándose una modalidad imprudente ${ }^{4}$.

Sin embargo, nuestro ordenamiento jurídico no contempla hasta la fecha figuras penales que sancionen directamente la contaminación del suelo o del aire, así como ocurre en la mayoría de las legislaciones occidentales ${ }^{5}$. En efecto, la única figura donde, de algún modo, se recoge la idea del castigo de la contaminación de esos espacios es la prevista en el art. 291 del Código Penal (en adelante, "CP”) 6 , que sanciona a los que propaguen indebidamente "organismos, productos, elementos o agentes químicos, virales, bacteriológicos, radiactivos, o de cualquier otro orden que por su naturaleza sean susceptibles de poner en peligro la salud animal o vegetal, o el abastecimiento de la población". La doctrina nacional ha sostenido que esta norma establece un delito de peligro para el medio ambiente ${ }^{7}$ y, como la disposición no limita los espacios en los que se pueden propagar componentes nocivos, el ilícito resulta idóneo para sancionar la contaminación del suelo o del aire.

En los últimos años, el Ministerio Público ha recurrido al delito de propagación indebida de contaminantes, previsto en el referido art. 291, para perseguir precisamente la alteración nociva de las condiciones normales del suelo o del aire. Así, v. gr., en agosto de 2017 se formalizó la investigación en contra de varias personas por ese delito, a causa de su presunta responsabilidad en la contaminación generada por una planta termoeléctrica en $\mathrm{Coronel}^{8}$; en noviembre de 2018, se formalizó la investigación en contra de otros sujetos en el contexto de graves incidentes que afectaron la calidad del aire de las localidades de Quintero y Puchuncavî́, y en junio de 2019 el antedicho trámite

${ }^{1}$ Véanse, $v$ gr., arts. 135 bis, 139 y 139 ter de la Ley General de Pesca y Acuicultura (1989), y art. 11 de la Ley $\mathrm{N}^{\circ} 20.962$ (2016).

2 Art. 44 de la Ley No 20.920 (2016).

${ }^{3}$ Art. $476 \mathrm{~N}^{\circ} 3$ del Código Penal, y arts. 22, 22 bis y 22 ter de la Ley de Bosques (1931).

${ }^{4}$ Art. 136 inc. $2^{\circ}$ de la Ley General de Pesca y Acuicultura (1989).

${ }^{5}$ Cfr. Matus et al., 2019, p. 360.

${ }^{6}$ Cfr. Matus, 2013, p. 138.

7 Muñoz y Fernández, 2010, p. 422.

${ }^{8}$ Https:/www.biobiochile.cl/especial/noticias/reportajes/reportajes-reportajes/2017/02/13/endesabajo-presion-por-contaminacion-en-bocamina-trabajadores-acusan-muertes-por-asbestos.shtml [Fecha de consulta: 24.04.2020].

${ }^{9}$ Https://www.t13.cl/noticia/nacional/agendan-audiencia-formalizacion-emergencias-ambientalestalcahuano-y-quintero-puchuncavi [Fecha de consulta: 24.04.2020]. 
procesal tuvo lugar por un derrame de petróleo que contaminó tierras indígenas en la Región de Atacama ${ }^{10}$. Como se puede apreciar, el ilícito del art. 291 del CP ha jugado un papel importante en la persecución de graves episodios de daño ambiental ocurridos en Chile, aunque hasta la fecha no se cuente con sentencias relevantes en la materia.

Ahora bien, así como ocurre con gran parte de los delitos que afectan el medio ambiente, el tipo de propagación indebida de contaminantes se cometerá, muy frecuentemente, por una o más personas con ocasión del trabajo que desempeñen en el seno de una empresa. Como nuestro Derecho no contempla una responsabilidad criminal de las

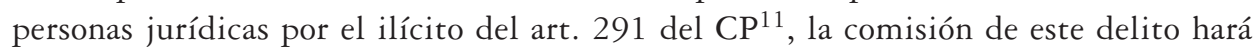
indispensable establecer el o los integrantes de la organización empresarial a quienes se debe imputar individualmente el injusto.

El objetivo del presente artículo es dilucidar cuáles son las reglas que permiten atribuir una responsabilidad individual por el delito de propagación indebida de contaminantes, cuando este se comete en el ámbito empresarial, y qué dificultades puede presentar la aplicación de aquellas, especialmente cuando se trata de hacer responsables como autores a los órganos superiores de una empresa. Para alcanzar este objetivo, el trabajo se dividirá en cinco partes. En la primera se destacará la importancia de llevar a cabo un análisis jurídico enfocado en los procesos de la respectiva organización empresarial, como cuestión previa al juicio de imputación individual (a continuación, II). Luego se enunciarán las reglas que permiten atribuir una responsabilidad penal individual por el delito del art. 291 del CP (infra III). Seguidamente, en las partes medulares del trabajo, se explicará el rendimiento de esas reglas de imputación, para ello se distinguirá entre la responsabilidad penal que puede afectar al personal subordinado, y aquella que puede recaer en los órganos superiores de una empresa (infra IV y V). Finalmente, se expondrán las conclusiones (infra VI).

\section{Cuestión PREVIA A LA IMPUTACiÓN INDIVIDUAL POR EL DELITO DEL ART. 291 DEL CP COMETIDO EN EL SENO DE UNA EMPRESA}

Desde la dictación en 1990 de la sentencia recaída en el conocido caso alemán del "espray para cuero" 12 , un sector representativo de la doctrina penal entiende que, antes de llevar a cabo el juicio de imputación a personas físicas por delitos cometidos en el ámbito empresarial, es necesario realizar un análisis jurídico enfocado en los procesos de la propia organización ${ }^{13}$. De este modo, es indispensable preguntarse si la afectación al respectivo bien jurídico es “imputable objetivamente” a la empresa ${ }^{14}$, partiendo del

${ }^{10} \mathrm{Https} / /$ www.cooperativa.cl/noticias/pais/region-de-atacama/copiapo-formalizan-a-trabajador-deminera-maricunga-por-derrame-de/2019-06-22/103957.html [Fecha de consulta: 24.04.2020].

11 Véase art. 1 inc. $1^{\circ}$ de la Ley $\mathrm{N}^{\circ} 20.393$ (2009).

12 BGHSt 37, 106.

13 Sobre este enfoque, véase Feijoo, 2007, pp. 181 ss.; Kuhlen, 1994, pp. 93 ss.

${ }^{14}$ Cfr. Feijoo, 2007, pp. 181 ss., quien alude a la "imputación objetiva al colectivo". 
supuesto de que esta tuviera la capacidad de actuar jurídico-penalmente. Lo anterior comporta indagar, por una parte, si los procesos que tuvieron lugar al interior de la respectiva organización fueron los que pusieron en peligro el respectivo bien jurídico o los que causaron su lesión, y, por otra, si estos procesos cumplieron las exigencias impuestas por el orden primario de conducta para la eliminación o disminución de riesgos ${ }^{15}$. De esta manera, habrá que establecer, $v$. $g r$. si la muerte de un consumidor fue causada por una falla de fabricación del producto elaborado por la compañía $X$; o si el funcionamiento de la planta que pertenece a la empresa $Z$, y que generó riesgos para el medio ambiente, se ajustó a las reglas técnicas de gestión medioambiental aplicables. Por cierto, si la afectación al respectivo bien jurídico no puede ser atribuida objetivamente a la organización, ya no tiene sentido plantearse qué integrantes de esta deben responder penalmente por el menoscabo ${ }^{16}$. Así ocurrirá, volviendo a los ejemplos recién mencionados, si la muerte del consumidor tuvo como única causa una grave enfermedad que le aquejaba; o si los peligros para el medio ambiente, que tienen su origen en la operación de la planta, constituyen riesgos tolerados por el Derecho ${ }^{17}$. En estos casos, la afectación al bien jurídico es típicamente irrelevante y, al no ser posible apreciar injusto alguno, ya no tiene sentido preguntarse qué personas físicas pertenecientes a la empresa tienen que responder penalmente ${ }^{18}$.

Así pues, el análisis jurídico previo centrado en el funcionamiento de la propia organización empresarial evita tener que abordar complejas cuestiones de responsabilidad individual al interior de la empresa, cuando el respectivo peligro o lesión para el bien jurídico no es atribuible a esta. Aun así, no es solo la necesidad de eludir explicaciones innecesarias la que hace conveniente el análisis enfocado en la organización. También la circunstancia de que en el ámbito empresarial el orden primario frecuentemente no distinga entre individuos y actores colectivos como sus potenciales destinatarios ${ }^{19}$, y que muchas veces establezca exigencias referidas solo a las condiciones que debe cumplir la operación de ciertas industrias o fábricas ${ }^{20}$, hace que el enfoque en el funcionamiento de estas permita considerar tal orden primario para excluir aquellos outputs empresariales irrelevantes para el Derecho penal.

Pues bien, aplicando el análisis enfocado en los procesos de la organización empresarial al ilícito del art. 291 del CP, tendremos que preguntarnos si los componentes nocivos a que alude el precepto provienen del proceso industrial de una determinada empresa, y si este proceso incumple las exigencias impuestas por el orden primario. En caso de que se satisfagan estas dos condiciones, deberemos indagar seguidamente

15 Por orden primario entendemos aquella porción del Ordenamiento que establece prohibiciones y mandatos destinados a la protección de bienes jurídicos ( $c f r$. Murmann, 2017, §8 nm. $6 \mathrm{~s}$.).

16 FejJoo, 2007, p. 184.

${ }^{17}$ Cfr. Feijoo, 2007, pp. $182 \mathrm{~s}$.

${ }^{18}$ Cfr. Feijoo, 2007, p. 184.

19 Weiss, 2008, p. 513.

${ }^{20}$ Por ejemplo, condiciones referidas a la infraestructura de plantas industriales, a los índices máximos de emisión de contaminantes, etc. 
a qué personas dentro de la respectiva organización empresarial corresponde imputar individualmente el tipo penal del art. 291.

\section{RELEVANCIA DE LAS REgLAS QUE RIGEN LA AUTORÍA Y PARTICIPACIÓN DELICTIVA EN EL JUICIO DE IMPUTACIÓN INDIVIDUAL POR EL DELITO DEL ART. 291 DEL CP}

El juicio de imputación individual por el delito del art. 291 del CP, cuando este se comete en el ámbito empresarial, tiene que realizarse de acuerdo con las reglas que rigen la autoría y participación delictiva ${ }^{21}$. Luego, es necesario establecer respecto de qué miembro de la organización se reúnen los presupuestos de la autoría inmediata o directa y, si en el hecho han intervenido dos o más personas, respecto de quiénes se satisfacen los requisitos de la autoría mediata, de la coautoría, de la inducción o de la complicidad ${ }^{22}$. Es importante tener presente que estas figuras dan forma a las reglas de imputación que permiten resolver los casos de concurso de personas en el delito. Debido a que será frecuente que, en el ámbito del Derecho penal de la empresa, intervenga más de un sujeto en un mismo hecho punible, las pautas que permiten la atribución punitiva al interior de la organización empresarial son, precisamente, aquellas que rigen la autoría inmediata o directa, la mediata, la coautoría y las distintas formas de participación. Por lo demás, no existe un sistema de reglas distinto al que rige la autoría y participación que permita guiar, con una dosis mínima de seguridad jurídica, el proceso de atribución de responsabilidad individual por el delito del art. 291 cuando este se comete en el seno de una empresa.

Es importante prevenir que la posición que un sujeto ocupe dentro de la organización empresarial, como la de gerente general, jefe de una área determinada, trabajador a cargo de un proceso específico, etc., no es un factor decisivo para la atribución de responsabilidad individual por el delito del art. 291 del CP. Es cierto que esa posición facilita la tarea de conocer qué deberes primarios de conducta tenían que cumplir los distintos miembros de la organización empresarial ${ }^{23}$, además de ser útil para identificar

${ }^{21}$ Afirman la necesidad de acudir a las reglas de autoría y participación para atribuir una responsabilidad penal individual por delitos medioambientales cometidos en organizaciones empresariales, GóRrIz, 2015, pp. 113 ss.; Kloepfer y Vierhaus, 1995, nm. 62 s.; Rudolphi, 1987, pp. 870 ss.; Saliger, 2012, nm. 157.

${ }^{22}$ Aunque en el Derecho positivo chileno el encubrimiento es considerado una forma de participación, la doctrina ha sostenido que, en rigor, no constituye una genuina modalidad de intervención delictiva; por todos, Politoff et al., 2004, pp. 433 y s.

${ }^{23}$ El lugar que el individuo ocupe en el organigrama de la empresa permite muchas veces establecer qué prohibiciones y mandatos debía cumplir en el contexto de la actuación colectiva empresarial. Sin embargo, este es un asunto que se sitúa en el plano del orden primario de comportamiento, y solo forma parte de un paso intermedio en el proceso de atribución de responsabilidad penal al sujeto. En efecto, la declaración de culpabilidad de este, y la imposición de una pena a su respecto, presupone no solo que el sujeto haya infringido la prohibición o mandato que tenía que observar, sino además la existencia de una norma de sanción penal que castigue expresamente (!) la infracción de tal prohibición o mandato. 
el círculo de potenciales autores o partícipes del ilícito ${ }^{24}$. Sin embargo, no es el lugar que un sujeto haya ocupado en la organización lo que permite fundar su responsabilidad, sino el que este haya realizado una conducta ${ }^{25}$ que pueda ser castigada conforme a la norma de sanción de autoría inmediata del delito de propagación indebida de contaminantes (art. 291 del CP), a las normas de sanción de coautoría o autoría mediata de dicho delito (art. 291, en relación con el art. 15, ambos del CP) o, finalmente, a las normas sancionatorias de participación de ese ilícito (art. 291, en relación con los arts. $15 \mathrm{~N}^{\circ} 2$, $2^{a}$ parte, y 16, todos del CP). Ciertamente, el art. 291 así como los arts. 15 y 16, todos del Código punitivo, permiten configurar distintas normas de sanción, es decir, tipos penales, que castigan diferentes formas de conducta, las que corresponden a cada una de las modalidades de autoría y participación del delito de propagación de contaminantes ${ }^{26}$. Así, $v$. gr. la conducta de propagar indebidamente elementos contaminantes por medio de la propia actuación corporal se castiga mediante la norma de sanción de autoría inmediata del art. 291; la conducta de propagación indebida realizada junto con otras personas en división del trabajo se castiga por medio de las normas de sanción de coautoría del art. 291, en relación con los números 1 y 3 del art. 15, etc. En suma, lo decisivo para hacer responsable a un miembro de la organización empresarial por el delito en cuestión es que este haya desplegado un comportamiento castigado por alguna de las normas de sanción que se configuran por medio de los arts. 291, 15 y 16, todos del CP.

Ahora bien, habiendo aclarado cuáles son las reglas que permiten imputar una responsabilidad individual por el delito del art. 291 -cuando este se comete en ámbitos empresariales-, corresponde en lo que sigue abordar las cuestiones o dificultades que pueden presentarse en la aplicación de aquellas. Para tal fin es necesario distinguir entre la responsabilidad que puede recaer en el personal subordinado, por una parte, y aquella que puede afectar a los órganos superiores de la empresa, por otra. Por "personal subordinado" entendemos aquellos miembros de la organización que ocupan una posición jerárquica inferior, y que están obligados a obedecer las órdenes que se les imparten. Los “órganos superiores”, en cambio, son aquellos integrantes de la empresa con la potestad de dictar instrucciones que son acatadas por los trabajadores de los niveles inferiores. A esta segunda categoría pertenecen no solo los órganos directivos, sino también los mandos medios. En las páginas siguientes abordaremos bajo qué título de intervención delictiva es posible sancionar a los miembros de la empresa que ocupan posiciones de subordinación, y a aquellos que tienen potestad de mando, así como las cuestiones o dificultades que pueden presentarse respecto de la aplicación de los distintos títulos de

${ }^{24}$ Así, $v$. gr., todos aquellos miembros del colectivo que, por su posición, intervengan en el proceso de emisiones de una determinada planta industrial, podrían haber intervenido -teóricamente- como autores o partícipes en la propagación de los elementos contaminantes a que alude el art. 291.

${ }^{25}$ Cfr. Díaz y García, 2007, p. 120; Matus, 2017, pp. 313 s. Del art. 19 No 3 inc. final de la Constitución se infiere que la legislación penal solo puede castigar determinados comportamientos que infringen una prohibición o un mandato. Acerca del "principio de la conducta” y su consagración constitucional, véase MATuS y RAmírez, 2019, pp. 85 ss.

${ }^{26}$ Respecto de las reglas de intervención delictiva como normas de sanción, Freund y RosTALSKI, 2019, § 10 nm. 7 s., 11 y 23. 
intervención. Como veremos, los problemas que suscitan las reglas de autoría y participación en el contexto del delito del art. 291 del CP son mucho mayores tratándose de los órganos superiores, lo que justifica un tratamiento más detallado de este punto.

\section{LA IMPUTACIÓN DE RESPONSABILIDAD PENAL}

\section{AL PERSONAL SUBORDINADO}

Si el delito del art. 291 del CP se comete al interior de una organización empresarial, lo habitual será que una o más personas que ocupan posiciones de subordinación sean los autores inmediatos del hecho, porque ellas realizarán personalmente, es decir, mediante su propia actuación corporal ${ }^{27}$, la acción de "propagar" los elementos contaminantes a que se refiere el precepto. Efectivamente, en virtud del principio de división del trabajo, conforme al cual todas las empresas se organizan, los trabajadores serán quienes generalmente estén en contacto directo con estos elementos y, por lo tanto, en condiciones de propagarlos personalmente, esto es, de difundirlos, esparcirlos o derramarlos "de propia mano" 28 , abriendo cañerías o compuertas, trasladándolos en vehículos y vertiéndolos en lugares prohibidos, etcétera.

En caso de que un trabajador incurra en la conducta típica del art. 291, lo más frecuente será que lo haga ejecutando la instrucción impartida por un superior jerárquico, y conociendo los peligros que ella implica para el medio ambiente. De ser así, el trabajador no podrá eximirse de responsabilidad señalando que simplemente cumplió una orden, ya que habrá realizado dolosamente todos los elementos objetivos del tipo ${ }^{29}$. Si el empleado acató la orden por temor a perder su puesto de trabajo, o a sufrir otro tipo de represalia, deberá analizarse en el caso concreto si se reúnen las exigencias del estado de necesidad exculpante (art. $10 \mathrm{~N}^{\circ} 11$ del CP), o bien, del miedo insuperable (art. $10 \mathrm{~N}^{\circ} 9$ del CP). En el evento de no satisfacerse esas exigencias, el injusto realizado seguirá siendo culpable, aunque podrá morigerarse la pena por la vía de una eximente incompleta.

Por otra parte, si al cumplir la instrucción el empleado no es capaz de comprender el alcance y las consecuencias de su conducta de propagación, debido, $v$. gr., a la complejidad de los procesos internos de la organización en que se desempeña, o a la apariencia externa de los elementos contaminantes, su actuación será atípica, debido a que el delito del art. 291 exige dolo y el CP no contempla una modalidad imprudente. El dolo del trabajador tendrá que abarcar siempre la conducta típica y su objeto material, esto es, la naturaleza de los elementos o agentes que se propagan ${ }^{30}$.

${ }^{27}$ De la autoría inmediata como realización típica producida mediante el propio cuerpo, véase BoTTKE, 1999, p. 25; KreuZberg, 2019, p. 373; SCHild, 2017, nm. 48.

28 Referente al significado de la acción típica de "propagar" como "difundir, esparcir o derramar", Garrido y CASTro, 2010, p. 141.

${ }^{29}$ Cfr. Schall, 1996, p. 102.

${ }^{30}$ Besio, 2019, p. 260. 


\section{LA IMPUTACión DE RESPONSABILIDAD PENAL A LOS ÓRGANOS SUPERIORES DE LAS EMPRESAS}

\section{Consideraciones previas}

Antes de examinar las dificultades que pueden presentarse en la aplicación de las reglas de intervención delictiva para hacer responsables a los órganos superiores por la comisión del delito previsto en el art. 291 del CP, conviene recordar lo que ya se destacó en supra III., a saber: no es la posición que ocupe un sujeto en la organización la que permite fundar su responsabilidad por los delitos cometidos en el ámbito empresarial, sino una conducta típica de autoría o participación realizada por aquel ${ }^{31}$. La sola circunstancia de haber ocupado el cargo de representante legal de una persona jurídica en cuyo seno se ha causado un daño al medio ambiente, o el mero hecho de haber tenido un cargo de dirección en ella, no permite declarar la culpabilidad de un sujeto e imponerle una pena $^{32}$. Una sanción basada únicamente en la posición que este ocupaba en la empresa sería una muestra de pura responsabilidad objetiva, contraria a un Derecho penal de la culpabilidad como el nuestro ${ }^{33}$.

Con lo anterior no se pretende desconocer que las personas que ocupan cargos directivos o con poder de mando en una empresa son las únicas que tienen la facultad de configurar los procesos financieros, productivos, de contratación de personal, etc., de la respectiva organización, y de tomar decisiones en estas materias de un modo autónomo, y excluyendo la intromisión de terceros. Tampoco se pretende negar que, como contrapartida a esa facultad, el Derecho puede obligar legítimamente a quienes la tienen, a que su ejercicio no implique peligros desaprobados para el medio ambiente u otros bienes jurídicos. Sin embargo, lo anterior solo significa que los órganos superiores de la empresa tienen que observar escrupulosamente ciertas normas de comportamiento impuestas por el orden primario. El que la infracción de esas normas pueda ser castigada por la vía del delito de propagación indebida de contaminantes es un problema distinto, y presupone, como ya se ha señalado, que tal infracción pueda subsumirse en el tipo de autoría inmediata de dicho delito, en los tipos de coautoría o autoría mediata del mismo o, finalmente, en los tipos de participación.

Ahora bien, el tipo penal que con mayor frecuencia entrará en consideración para sancionar la infracción del orden primario cometida por un órgano superior será el de inducción (art. 291, en relación con el art. 15 N 2, $2^{\text {a }}$ parte, del CP). Ciertamente, cuando este órgano intervenga en el delito en cuestión, lo hará habitualmente impartiendo

${ }^{31}$ Incluso es dudoso que, en el campo de los delitos de omisión impropia, el lugar que ocupe un directivo en la empresa permita fundar el deber de evitar resultados lesivos (así, Frisch, 2018, p. 133).

32 MuÑOz et al., 2015, p. 203.

33 En esta línea, Hernández, 2008, p. 176; MuÑoz et al., 2015, p. 203. 
una orden a uno o más trabajadores determinados, para que estos, en calidad de autores inmediatos plenamente responsables, propaguen elementos nocivos.

\section{La sanción de los órganos superiores en calidad de inductores del delito previsto en el art. 291 del CP}

Para sancionar a un órgano directivo a título de inducción del delito previsto en el art. 291 del CP, deberán concurrir los requisitos generales que exige esta forma de participación. Así, en el plano objetivo, el trabajador instigado tendrá que haber realizado una conducta típica y antijurídica en el sentido del delito mencionado, que alcance a lo menos el estadio de la tentativa. Sin un hecho principal de esas características, no será posible castigar al órgano superior.

Por otra parte, el referido órgano tiene que haber causado, por medio de la orden que impartió, la resolución criminal en el subalterno, lo que implica que la actuación de aquel tiene que haber sido conditio sine qua non de la resolución delictiva ${ }^{34}$. Para provocar esta, no se exige que haya existido una relación personal y estrecha con el trabajador, ni tampoco una comunicación directa (“cara a cara”) con él, por lo que podría bastar una instrucción escrita para formar su voluntad de realizar el delito ${ }^{35}$.

Para castigar a un órgano directivo como inductor, es indispensable que este, además de haber causado la resolución criminal mediante la orden impartida, haya creado un riesgo jurídicamente desaprobado de provocar tal resolución. Esta exigencia se cumplirá cuando la conducta del órgano directivo tenga una "referencia de sentido delictiva", es decir, cuando esta conducta, por su sentido, haya estado dirigida claramente a causar un designio criminal en el empleado ${ }^{36}$. Por ello, la sola creación de una oportunidad favorable que haga caer al trabajador en la "tentación" de realizar el delito $-v$. gr., ordenarle que custodie ciertos elementos contaminantes susceptibles de ser propagados- no es suficiente para fundar una inducción ${ }^{37}$. En este caso, el comportamiento del órgano superior tiene un sentido ambivalente, ya que también puede ser interpretado como una manifestación legítima del ejercicio de sus facultades de dirección en la empresa.

Adicionalmente, el art. $15 \mathrm{~N}^{\circ} 2$ del CP exige que la inducción sea "directa". Este requisito excluye la punibilidad de la instigación "en cadena” o sucesiva ${ }^{38}$. En consecuencia, si un órgano superior persuade a un mando medio para que este, a su vez, provoque en un trabajador la resolución de cometer el delito del art. 291, la conducta del primero será atípica. El texto del art. $15 \mathrm{~N}^{\circ} 2$ no es obstáculo, sin embargo, para castigar la "coinducción", la que se presentará cuando varios ejecutivos acuerden en

\footnotetext{
${ }^{34}$ Cfr. Murmann, 2017, § 27 nm. 97.

35 KaSPar, 2017, nm. 9.

36 De la "referencia de sentido delictiva" como elemento fundante de la inducción, FrisCH, 1988,

${ }^{37}$ Cfr. Mansdörfer, 2011, nm. 790.

38 Por todos, véase Hernández, 2011b, pp. 409 ss., con ulteriores referencias.
} pp. 335 ss. 
común persuadir a uno o más trabajadores concretos para que estos propaguen elementos contaminantes y, repartiéndose tareas, los determinen a hacerlo ${ }^{39}$.

En lo tocante al plano subjetivo, el tipo de inducción requiere dolo, dirigido tanto a la acción de participación consistente en formar en el trabajador la voluntad de cometer el delito del art. 291 como también a la consumación del hecho principal.

A modo de recapitulación podemos señalar: siempre y cuando no estemos frente a un caso de inducción "en cadena”, los órganos superiores de la empresa responderán como instigadores del delito previsto en el art. 291 del CP cuando, por medio de la orden que impartan, causen en el subalterno la resolución criminal de cometer el ilícito.

Ahora bien, para un sector representativo de la doctrina, la atribución de responsabilidad penal a los órganos superiores solo a título de inducción no reflejaría a cabalidad el papel decisivo que estos pueden cumplir en la realización de delitos en el seno de la empresa ${ }^{40}$. Ese sector afirma que, al impartir la respectiva orden al empleado, los sujetos con poder de mando en la organización empresarial son frecuentemente los configuradores centrales del suceso delictivo, y ello obligaría a juzgarlos como agentes que tienen el verdadero control del hecho punible, es decir, como autores.

Una primera forma de intervención delictiva que podría entrar en consideración para sancionar a los órganos directivos como autores del delito del art. 291 es la autoría mediata.

\section{La sanción de los órganos superiores en calidad de autores mediatos del delito previsto en el art. 291 del CP}

Los órganos superiores de una empresa podrían ser responsables por el delito del art. 291 en calidad de autores mediatos, si realizan la propagación de contaminantes por medio de uno o más trabajadores de los que se sirvan como instrumento. El dominio de la voluntad de los órganos superiores podría basarse en la causación o en el aprovechamiento de un error, o bien, en el ejercicio de coacción. El superior provocará o se aprovechará de una situación de error del trabajador en todos aquellos casos en que le imparta una instrucción que conduzca a una propagación indebida de elementos contaminantes, sin que los efectos nocivos para el medio ambiente que importa la ejecución de la orden puedan ser advertidos por el empleado ${ }^{41}$. Por otra parte, si el órgano superior ejerce

\footnotetext{
39 Cfr. Heine, 1995, p. 106.
}

${ }^{40}$ Véase, por ejemplo, Frisch, 2018, p. 125.; Feijoo, 2007, p. 156, con ulteriores referencias. En efecto, aunque en nuestro Ordenamiento los inductores sean sancionados con la misma pena que corresponde a los autores, una declaración de culpabilidad basada en el art. $15 \mathrm{~N}^{\circ} 2,2^{\mathrm{a}}$ parte, del CP refleja solo una participación marginal en el hecho. Asimismo, el ámbito de punibilidad de la instigación es notablemente más limitado que el de la autoría, porque aquella solo se sanciona en la medida que acceda a una conducta principal realizada por un autor, que sea típica y antijurídica, y que se encuentre por lo menos en fase de tentativa; además, la instigación no es punible bajo las formas imperfectas de ejecución del art. $7^{\circ}$ del $\mathrm{CP}$ (Couso, 2013, pp. 623 s.).

${ }^{41}$ Cfr. Schmitz, 2019, nm. 141. Se debe precisar que en virtud del principio de confianza que rige en la división del trabajo empresarial, el personal subordinado no tiene, por regla general, la obligación 
presión al trabajador, reduciendo el papel de este al de mero instrumento por medio del que se ejecuta el acto de contaminación, también podrá aplicarse la figura de la autoría mediata $^{42}$. Para ello será necesario que la coacción ejercida hacia el empleado haya alcanzado una intensidad tal que permita excluir su culpabilidad según las reglas del estado de necesidad exculpante ${ }^{43}$.

Ahora bien, en aquellos casos en que uno o más trabajadores hayan propagado contaminantes de manera plenamente responsable, es decir, de un modo doloso y culpable, sería muy discutible sancionar a los órganos superiores como autores mediatos. Ello solo tendría cabida si se aplicara la figura de los aparatos organizados de poder al ámbito empresarial.

La figura de los aparatos organizados de poder constituye una modalidad de autoría mediata desarrollada en los años sesenta del siglo pasado para el enjuiciamiento de "autores o delincuentes de escritorio”, quienes habían intervenido en homicidios masivos planeados burocráticamente y ejecutados durante el régimen nacionalsocialista ${ }^{44}$. En virtud de esta modalidad de autoría, era posible hacer responsables a funcionarios que no habían realizado de propia mano la acción típica de homicidio, pero que habían impartido la orden de matar a numerosas víctimas. La razón para considerar a estos funcionarios como autores (mediatos) de los homicidios consistía en la fungibilidad sin límites de los autores directos. Ciertamente, estos representaban simples piezas intercambiables en el "engranaje" del aparato de poder estatal, lo que garantizaba a los "autores o delincuentes de escritorio", que habían dictado las órdenes correspondientes, la realización de los homicidios y les permitía dominar el suceso 45 .

En las últimas décadas, el Tribunal Supremo Federal alemán ha extendido el campo de aplicación de la figura de los aparatos organizados de poder más allá de estructuras políticas, militares o policiales que se apoderan del Estado y lo utilizan para sus fines delictivos. Así, el Bundesgerichtshof ha entendido que en el ámbito empresarial también se pueden presentar casos de dominio por organización, cuando los superiores jerárquicos se aprovechan de "condiciones marco" de la respectiva empresa, que les permiten asumir de facto el acatamiento de sus instrucciones por parte de algún subalterno, al igual que acontece en los supuestos para los que dicha figura fue concebida originalmente ${ }^{46}$.

de revisar la adecuación a Derecho de las actuaciones instruidas por el superior. Tal principio solo deja de regir en favor del empleado cuando existen indicios de que la instrucción recibida es contraria a deber y su ejecución puede significar un daño ambiental. Sobre el principio de confianza en el ámbito empresarial véase Hernández, 2008, pp. 191 ss.; PiÑa y Cox, 2013, pp. 185 ss.

${ }^{42}$ Cfr. Górriz, 2015, p. 122.

43 Roxin, 2003, § 25 nm. 48.

${ }^{44}$ Fundamental, Roxin, 1963, pp. 193 ss.; Roxin, 2003, § 25 nm. 105 ss.

45 Roxin, 2003, § 25 nm. 107.

${ }^{46}$ BGH NJW 98, 767; BGHSt 48, 331, 342; 49, 147, 163 s. 
La doctrina mayoritaria rechaza con buenas razones la aplicación de la figura de los aparatos organizados de poder al ámbito empresarial ${ }^{47}$. Así, se señala que en este campo no concurre la fungibilidad de los autores directos que exige el dominio por organización, ya que en una empresa que participa en el tráfico económico ajustándose a las exigencias que impone la ley, no es esperable que la generalidad de sus empleados obedezca instrucciones antijurídicas ${ }^{48}$. Asimismo, en aquellos casos - particulares- en que algún trabajador ejecute una orden antijurídica, este lo hará de manera plenamente responsable, lo que es una clara muestra de que, conforme con las valoraciones del Derecho, su conducta no fue dominada por nadie más que por él mismo ${ }^{49}$. La mera circunstancia de que una persona autorresponsable cumpla una directriz ilegal que se le imparta en el contexto laboral, no permite fundar el dominio del hecho punible por parte del superior ${ }^{50}$, sino únicamente un caso de inducción.

A modo de recapitulación podemos señalar: los órganos superiores de una empresa responderán como autores mediatos del delito de propagación indebida de contaminantes solo en aquellos casos en que hayan instrumentalizado a sus subordinados por la vía del error o de la coacción.

4. ¿Sanción de los órganos superiores en calidad de coautores del delito previsto en el art. 291 del CP?

Otra forma de autoría que podría entrar en consideración para sancionar a los órganos superiores por su intervención en el delito del art. 291 del CP es la coautoría. Sin embargo, y como se verá en lo que sigue, resulta difícil que los presupuestos que exige esta figura se reúnan en el caso dado.

En efecto, para sancionar a un órgano superior de la empresa como coautor del delito del art. 291 tendría que haber existido, en primer lugar, una decisión de realizar el hecho en común, es decir, un acuerdo entre el órgano y otros miembros de la empresa $-v$. gr. determinados empleados-, para ejecutar el delito de manera conjunta y con división del trabajo ${ }^{51}$. Una actuación colectiva consciente no basta para estar en presencia de tal acuerdo; es indispensable, además, una voluntad de los intervinientes de realizar el delito en común ${ }^{52}$. Sin esa voluntad no es posible gravar a cada uno de los coautores también con el aporte de los demás, ni tampoco resolver los casos de exceso que se puedan presentar ${ }^{53}$. Pues bien, de la (mera) circunstancia de que el empleado cumpla la orden antijurídica que se le imparte, y sea consciente del carácter delictivo de su actuar,

${ }^{47}$ Por todos, Bosch, 2002, pp. 241 ss., 586; Frisch, 2018, pp. 126 s.; Roxin, 2003 , § 25 nm. 129 ss.; Wessels et al., 2019, nm. 853.

48 Roxin, 2003, § 25 nm. 130.

${ }^{49}$ Murmann, 2017, § $27 \mathrm{~nm} .48$.

${ }^{50}$ Frisch, 2018, pp. 126 s.

51 Cfr. Murmann, 2017, § 27 nm. 57.

52 KRÄMER, 2015, p. 273.

${ }^{53}$ Cfr. Bosch, 2002, p. 273. 
no podría inferirse que este haya querido una realización del hecho en conjunto con el superior, de acuerdo con una determinada división del trabajo ${ }^{54}$.

El segundo presupuesto que debería concurrir para sancionar a los órganos directivos como coautores del delito del art. 291 del CP es que hayan tomado parte en la ejecución en común del ilícito ${ }^{55}$. Ello exige que dichos órganos hayan hecho un aporte esencial para la propagación de contaminantes, de conformidad con la división de labores previamente acordada. No hay duda de que esta exigencia se cumplirá cuando el órgano superior haya realizado un aporte fundamental durante la etapa de ejecución del ilícito. Así ocurrirá, $v$. gr., en el caso de que un ejecutivo y un trabajador hayan abierto de manera coordinada determinadas compuertas de una pequeña planta de tratamiento de aguas servidas, vertiendo elementos líquidos sin purificar a un terreno adyacente. Sin embargo, este tipo de casos se presentará con muy poca frecuencia. Lo habitual será que los aportes de los directivos para cometer el delito del art. 291 no se hagan en la etapa de su ejecución, sino antes. Aquí corresponde plantear la importante cuestión de si el órgano directivo, que incide únicamente en el estadio preparatorio del delito, puede ser considerado como coautor. Un sector representativo de la doctrina sostiene que, en tanto en cuanto un sujeto haya participado decisivamente en la planificación del hecho (con la que los restantes coautores manifestaron su acuerdo), su minus de intervención en la etapa de ejecución material se compensaría por el plus de planificación configuradora del delito y, en consecuencia, podría ser sancionado como coautor ${ }^{56}$. En cualquier caso, esta participación decisiva exigiría que, en la fase de preparación del hecho, el sujeto haya determinado suficientemente qué personas realizarán el delito, cuál será el objeto de la acción típica, cuáles serán los medios para afectar el respectivo bien jurídico, qué magnitud alcanzará su lesión, así como toda otra clase de circunstancias típicas relevantes, de tal modo que los sujetos que realicen materialmente el hecho tengan que decidir únicamente "si" lo cometen, pero no "cómo" cometerlo 57 . Tratándose del delito del art. 291 del CP, estas condiciones que debería reunir la planificación del hecho, para considerar como coautor al órgano con poder de mando empresarial que la diseña, solo se verificarán en aquellos pocos casos en que este organice una actuación grupal de carácter más o menos complejo, e integrada por varios aportes individuales, y no en aquellos supuestos (mucho más frecuentes en la práctica) en los que el superior imparta una orden específica a uno o más trabajadores, como, $v . g r$, verter ciertos desechos en un descampado ${ }^{58}$. En este último grupo de casos, solo los trabajadores tendrán el dominio sobre la acción de propagar elementos contaminantes, porque serán ellos quienes

\footnotetext{
${ }^{54}$ KräMER, 2015, pp. 273 s.

55 Acerca del presupuesto de la coautoría consistente en la ejecución conjunta, véase MuRMANN, 2017, § 27 nm. 64 ss.

56 Por todos véase, Wessels et al., 2019, nm. 823 s., con abundantes ulteriores referencias.

${ }^{57} \mathrm{BosCH}, 2002$, p. 271.

${ }^{58}$ Cfr. Bosch, 2002, p. 272; SCHall, 1996, p. 103.
} 
decidirán no solo si ejecutan el delito del art. 291, sino también cómo hacerlo ${ }^{59}$; el sujeto con poder de mando únicamente podrá ser castigado como inductor.

5. ¿Sanción de los órganos superiores en calidad de autores inmediatos del delito del art. 291 del CP?

La última forma de autoría que podría entrar en consideración para sancionar a los órganos superiores de la empresa por la comisión del delito previsto en el art. 291 del $\mathrm{CP}$ es la autoría inmediata. El que esta modalidad de intervención delictiva respecto de dichos órganos sea muy poco frecuente justifica que la analicemos en el último lugar de las distintas formas de autoría aplicables.

En efecto, a diferencia de lo que ocurre con delitos de cuello blanco como la administración desleal o los ilícitos concursales, no será común que los órganos superiores de una empresa realicen de propia mano todos y cada uno de los presupuestos del tipo penal de propagación indebida de contaminantes ${ }^{60}$. Así, aunque dichos órganos hayan tenido a su cargo la administración de una fábrica o instalación cuyo funcionamiento causó que se propagaran elementos contaminantes, y hayan conocido además el potencial lesivo de su operación, por regla general no intervendrán en la realización del tipo penal "propagando" personalmente esos elementos, esto es, "difundiéndolos, esparciéndolos o derramándolos”61. Es importante advertir que el art. 291 castiga la realización de propia mano de la conducta de "propagar" indebidamente ciertos elementos, y no de la conducta de "gestionar", "organizar" o "dirigir" defectuosamente una fábrica o instalación cuya operación afecte el medio ambiente, comportamientos estos últimos que, desde el punto de vista fenomenológico, son los que podrían desplegar de manera directa los órganos superiores de una empresa. De este modo, es el propio verbo rector utilizado en el art. 291 el que reduce considerablemente las posibilidades de hacer responsables como autores inmediatos a dichos órganos.

El art. 291 del CP muestra claras diferencias con normas del Derecho penal medioambiental comparado, que no limitan las modalidades de acción típica y que constituyen delitos puramente resultativos, permitiendo castigar a título de autoría inmediata una amplia variedad de comportamientos ilícitos de los órganos directivos, bajo la única condición de que desencadenen un curso lesivo para el medio ambiente. Así, por ejemplo, el delito del art. 325.1 del Código Penal español sanciona a todo aquel que "provoque" o "realice" directa o indirectamente emisiones, vertidos, radiaciones, etc., que causen o puedan causar daños a la calidad del aire, del suelo o de las aguas, o a animales o plantas. Conforme con esta formulación legal, no es problemático considerar autor directo del hecho punible al administrador o alto directivo de la empresa que, $v$. gr. ha organizado defectuosamente los procesos de gestión de riesgos ambientales, o

59 SCHALl, 1996, p. 103.

${ }^{60}$ Sobre las dificultades que se presentan en el ámbito empresarial para hacer responsables a quienes no ejecutan directamente la acción típica, véase Couso, 2015, pp. 274 s.

61 Véase supra nota 28. 
ha seleccionado incorrectamente al personal que ocupa puestos críticos en la protección del medio ambiente, poniendo, de este modo, una condición necesaria para que se produzca un daño ecológico ${ }^{62}$.

\section{La figura del "actuar en lugar de otro" y la omisión impropia como mecanismos de imputación penal a los órganos superiores}

Con el objeto de captar adecuadamente la importancia que tiene la intervención de los órganos superiores de la empresa en la comisión del delito previsto en el art. 291, y ante las dificultades para castigarlos a título de autoría inmediata, coautoría o autoría mediata por aparatos organizados de poder, se podría pensar en sancionar a esos órganos conforme con la figura del "actuar en lugar de otro", o bien, según los principios que rigen la omisión impropia. A continuación, corresponde abordar la plausibilidad de ambas alternativas de solución.

a) ¿Responsabilidad de los órganos superiores por el delito previsto en el art. 291 del CP mediante la figura del "actuar en lugar de otro"?

La figura del "actuar en lugar de otro" está prevista con alcance general en el art. 58 inc. $2^{\circ}$ del Código Procesal Penal (en adelante, "CPP”), según este, por las personas jurídicas deben responder "los que hubieren intervenido en el acto punible". Como todas las empresas en que ejercen funciones órganos con poder de mando están constituidas como personas jurídicas, se podría plantear la cuestión de si esa norma permitiría atribuir responsabilidad penal a estos órganos por su intervención en el delito del art. 291 del $\mathrm{CP}$, sin necesidad de acudir a las reglas generales de autoría y participación.

Una lectura apresurada del art. 58 inc. $2^{\circ}$ del CPP podría llevar a la falsa conclusión de que este precepto permite simplificar el problema de atribución de responsabilidades al interior de una organización empresarial ${ }^{63}$, castigando a sus órganos superiores por el hecho de haber, de una u otra forma, "intervenido en el acto punible", con total independencia de que les sean aplicables las reglas de autoría y participación. Así, se podrían sortear todas las dificultades que surgen de la aplicación de dichas reglas y que pueden conducir a no castigarles como autores del delito de propagación de contaminantes.

Sin embargo, el sentido del art. 58 inc. $2^{\circ}$ del CPP no es, en caso alguno, el de suplir las reglas generales de intervención delictiva que resultan aplicables a los delitos

${ }^{62}$ Cfr. Muñoz et al., 2015, p. 201. Conductas como las de organizar defectuosamente los procesos de gestión de riesgos ambientales, o seleccionar incorrectamente al personal, no solo se castigan en la legislación hispana en caso de que el órgano directivo haya actuado con dolo, sino también cuando lo hubiera hecho con imprudencia grave (art. 331 del Código Penal español). Tratándose del art. 291 del CP, el favorecimiento del delito mediante la contratación negligente de un trabajador sumamente inexperto en materia de riesgos medioambientales, quien luego propaga elementos contaminantes, no es punible, porque la complicidad imprudente es atípica en nuestro Derecho (Politoff et al., 2004, pp. 426 y s., incluyendo nota 164).

${ }^{63}$ En esta misma línea, respecto de la figura del “actuar en lugar de otro” en el Derecho español, DíAz y GARCÍA, 2007, p. 120. 
cometidos en el seno de una persona jurídica, sino evitar la laguna de punibilidad que se produciría en los delitos especiales si quien realiza materialmente el hecho (un representante legal, un órgano directivo, etc.) no reúne la cualidad especial que sí concurre en la persona jurídica ${ }^{64}$. Es decir, de no ser por dicho precepto, la persona física que interviene en el hecho no podría ser sancionada, por carecer de la cualificación que exigen los tipos con sujeto activo nominado y que sí puede reunir la persona jurídica en el seno donde aquella se desempeña.

Establecido lo anterior, es posible señalar que al no ser el tipo del art. 291 del CP un delito especial, sino común, no es procedente aplicar a su respecto la figura del actuar en lugar de otro para hacer responsables a los órganos superiores de una empresa ${ }^{65}$. Ahora bien, aun cuando la propagación indebida de contaminantes fuera un ilícito especial, ello no significaría que el art. 58 inc. $2^{\circ}$ del CPP permita hacer responsables a dichos órganos simplemente por la posición jerárquica que ocupen en la organización, sino que siempre sería necesario que estos ejecuten (!) la acción típica de "propagar", al menos en calidad de autores mediatos. Como correctamente lo ha destacado la jurisprudencia española ${ }^{66}$, la figura del actuar en lugar de otro no compensa la falta de acción, sino "la ausencia de las características típicas de la autoría en la persona del autor”; por consiguiente, solo resulta aplicable "para tener por acreditadas estas características cuando el autor en todo caso ha realizado la acción típica”.

b) ¿Responsabilidad de los órganos superiores por el delito del art. 291 del CP sobre la base de la omisión impropia?

Ante las dificultades que presenta la atribución de responsabilidad a los órganos superiores de una empresa por el delito del art. 291 del CP, basada en un comportamiento activo de autoría inmediata, coautoría o autoría mediata, se podría proponer como alternativa imputar tal responsabilidad conforme a las reglas que rigen la comisión por omisión. De este modo, si el tipo del art. 291 pudiera interpretarse como un delito de omisión impropia, y si lograra fundarse una posición de garante de los órganos superiores, estos podrían ser sancionados penalmente en calidad de autores, en caso de no haber evitado que uno o más trabajadores propagaran elementos nocivos para los ecosistemas.

La doctrina alemana y española en materia de delitos ambientales ha tratado extensamente la responsabilidad de los órganos superiores fundada en conductas omisivas ${ }^{67}$. En el caso del Derecho alemán, Schmitz sostiene que estos órganos son garantes de vigilancia, teniendo, en consecuencia, el deber de evitar resultados lesivos para el medio

\footnotetext{
${ }^{64}$ En este mismo sentido, respecto del art. 31 del Código Penal español, Díaz y García, 2007, pp. 120 s.

${ }^{65}$ Así también, Matus, 2013, p. 150.

${ }^{66}$ STS de 3 de julio de 1992 (Rep. La Ley N 12.612).

${ }^{67}$ En el Derecho alemán, véase Schмiтz, 2019, nm. 142 ss., con ulteriores citas. En el Derecho español, por todos, Górriz, 2015, pp. 52 ss.
} 
ambiente que puedan tener su origen en la organización defectuosa de la empresa ${ }^{68}$. La posición de garante de los ejecutivos permitiría sancionarles por la infracción de obligaciones tales como la de ordenar la paralización de una actividad industrial contaminante, o disponer la realización de capacitaciones a los trabajadores acerca de riesgos ambientales, siempre y cuando el cumplimiento de estos mandatos hubiera evitado el resultado típico con una probabilidad rayana en la certeza.

Ahora bien, se hace indispensable aclarar que en Alemania y España es posible una responsabilidad de los órganos superiores fundada en una comisión por omisión porque varios delitos de acción contra el medio ambiente, previstos en sus respectivos ordenamientos, están concebidos como tipos penales de resultado. Según el $\S 13$ del Strafgesetzbuch y el art. 11 del Código Penal español, estos tipos también deben ser aplicados para castigar conductas omisivas que no hayan evitado el correspondiente resultado típico, en tanto en cuanto el omitente tenga una posición de garante y su comportamiento pueda considerarse como equivalente a la comisión del delito mediante un hacer. Los referidos preceptos habilitan, pues, a los tribunales a interpretar delitos de acción como delitos de omisión impropia.

Pues bien, es importante señalar que en Chile algunos autores han sostenido que el delito del art. 291 del CP permitiría sancionar no solo conductas activas, sino también omisivas. A esta conclusión llegan Muñoz y Fernández, quienes afirman que dicha norma tiene una estructura compleja y muestra una "configuración claramente resultativa”, ya que el comportamiento típico de propagar supone la "producción de un resultado en el plano físico-natural”, es decir, un "resultado de propagación”, por ejemplo, en forma de "vertido de organismos, productos, elementos o agentes químicos (...)"69. Estos autores agregan que un resultado como este podría ser causado por medio de conductas activas ( $v$. gr. " abrir el grifo para que salga el vertido"), o ser el fruto de comportamientos omisivos $(v \cdot g r$, " no reparar una cañería que se sabe que está en mal estado y que, en caso de romperse, puede producir unos vertidos"), los que quedarían equiparados a efectos de pena con las conductas activas ${ }^{70}$.

La opinión anterior, según esta, el tipo del art. 291 del CP puede ser interpretado como de resultado y, por consiguiente, de omisión impropia, es discutible ${ }^{71}$. Efectivamente, el tenor de ese precepto no contiene ningún elemento del que se pueda desprender que la consumación del ilícito requiera la modificación del sustrato material de un bien jurídico, o un determinado daño inmaterial del mismo. Por el contrario, su redacción indica que el tipo se cumple con la mera ejecución del acto de "propagar" 72 . Además, una interpretación sistemática del art. 291 nos permite concluir que estamos frente a un delito de mera actividad. En efecto, el precepto muestra claras diferencias con los arts. 289 y 290, que, estando también previstos en el $§ 9$ del T. VI del L. II del CP, sí

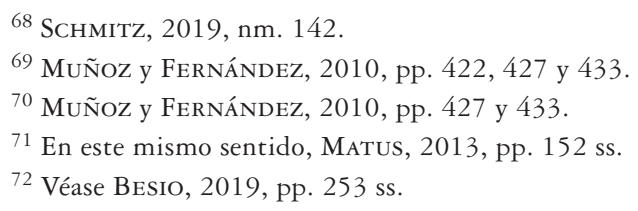


aluden a un resultado de la conducta de propagación, en forma de producción de una enfermedad de animales o una plaga de vegetales ${ }^{73}$. Por todo lo anterior, creemos que interpretar el art. 291 del CP como un ilícito de resultado, para permitir que el desvalor de conducta capte también omisiones, implica extender la punibilidad más allá de los límites del texto de la ley ${ }^{74}$.

Además, aun cuando se aceptara que el delito del art. 291 presupone un resultado típico, de ello no se sigue que se pueda equiparar valorativamente su producción y su no evitación. Una equiparación semejante infringiría el principio de reserva legal. En efecto, nuestro Derecho carece de una cláusula general de comisión por omisión, y la única norma que permitiría interpretar los delitos de resultado de acción como de omisión impropia, a saber, la contemplada en el art. 492 inc. $1^{\circ}$ del CP, solo es aplicable a los "crímenes y simples delitos contra las personas"75. Así, pues, castigar la comisión por omisión tratándose de ilícitos no incluidos en el Título VIII del Libro II de nuestro Código punitivo importaría una interpretación analógica in malam partem del art. $492^{76}$.

\section{Conclusiones}

Una vez establecido que los componentes nocivos a que alude el art. 291 del CP provienen del proceso industrial de una determinada empresa, y que tal proceso se ha apartado de las exigencias impuestas por el orden primario, es necesario imputar a personas físicas determinadas que trabajan en aquella la comisión del delito previsto en dicho precepto. La imputación individual debe realizarse según las reglas que rigen la autoría y participación. Estas reglas permiten sin dificultad hacer responsables como autores inmediatos a quienes forman parte del personal subalterno de la organización empresarial, porque ellos serán, habitualmente, quienes ejecuten personalmente la acción típica ("propagar") a que alude el artículo antedicho. En cambio, las reglas que regulan la intervención delictiva muestran claras limitaciones para fundar una responsabilidad a título de autoría de los órganos superiores de la empresa. En efecto, la contribución de estos órganos a la comisión del delito del art. 291 consistirá, en la mayoría de los casos, en haber impartido una orden a un subalterno plenamente responsable para que este propagara contaminantes. Sin embargo, la dictación de esa orden no está captada por el tenor literal del tipo de autoría inmediata de propagación indebida de contaminantes (art. 291 del CP). Tampoco resulta aplicable los tipos de coautoría (art. 291, en relación con el art. 15, números 1 y 3, ambos del CP), ya que el haber impartido una instrucción de que se propaguen elementos contaminantes no forma parte de una realización en común del hecho. Por su parte, la figura de la autoría mediata por aparatos

\footnotetext{
73 Besio, 2019, p. 253 ss.

74 Así también Matus, 2013, p. 146.

${ }^{75}$ Respecto de la omisión impropia en el Derecho chileno, véase Hernández, 2011 a, pp. 22 ss.

${ }^{76}$ En el entendido que el art. 492 efectivamente contemplara una cláusula de comisión por omisión.
} 
organizados de poder no resulta idónea para sancionar a los órganos superiores de una empresa. Por consiguiente, la contribución de estos a la comisión del delito de propagación indebida de contaminantes, en forma de instrucción a uno o más empleados, solo puede ser castigada mediante el tipo de inducción (art. 291, en relación con el art. 15 $\mathrm{N}^{\mathrm{o}} 2,2^{\mathrm{a}}$ parte, ambos del CP).

\section{BiBLIOGRAFÍA}

Besio, Martín, 2019: “Artículo 291”, en Jaime Couso y Héctor Hernández (directores), Código Penal comentado. Parte Especial. Libro Segundo Título VI, Santiago: Legal Publishing, pp. 249-261.

Bosch, Nikolaus, 2002: Organisationsverschulden in Unternebmen, Baden-Baden: Nomos.

BotTKe, Wilfried, 1999: "Criminalidad económica y Derecho criminal económico en la República Federal de Alemania”, Revista Penal, No 4.

Couso, Jaime (2015): "Intervención delictiva y organización. Necesidad y complejidades de una comparación funcional entre el derecho chileno y el derecho internacional y comparado", Revista Chilena de Derecho, vol. 42, No 1.

Couso, Jaime (2013): "Sobre el concepto material de autor. Consideraciones dogmáticas y metodológicas", en Alex van Weezel (editor), Humanizar y renovar el derecho penal. Estudios en memoria de Enrique Cury, Santiago: Thomson Reuters, pp. 619-657.

DíAZ y García, Miguel, 2007: "Problemas actuales de autoría y participación en los delitos económicos", Nuevo Foro Penal, $\mathrm{N}^{\circ} 71$.

Feijoo, Bernardo, 2007: Derecho penal de la empresa e imputación objetiva, Madrid: Reus.

Freund, Georg y Rostalski, Frauke, 2019: Strafrecht. Allgemeiner Teil (3 $3^{a}$ edición), Berlín: Springer.

FrISCH, Wolfgang, 2018: "Zur Verantwortlichkeit von Unternehmern und Unternehmensorganen für Straftaten ihrer Mitarbeiter. Zugleich ein Beitrag zur Lehre von der Täterschaft”, en Ulrich Stein (editor), Systematik in Strafrechtswissenschaft und Gesetzgebung. Festschrift für Klaus Rogall, Berlín: Duncker\&Humblot, pp. 121-146.

FrISCH, Wolfgang, 1988: Tatbestandsmäßiges Verhalten und Zurechnung des Erfolgs, Heidelberg: C.F. Müller.

Garrido, Mario y Castro, Álvaro, 2010: "Delincuencia medioambiental en Chile: alcances de una normativa inaplicable”, en Miguel Schweitzer (coordinador), Nullum crimen, nulla poena sine lege. Homenaje a grandes penalistas chilenos, Santiago: Ediciones Universidad Finis Terrae, pp. 125-157.

Górriz, Elena, 2015: Delitos contra los recursos naturales y el medio ambiente, Valencia: Tirant lo Blanch. HeIne, Günter, 1995: Die strafrechtliche Verantwortlichkeit von Unternehmen, Baden-Baden: Nomos. Hernández, Héctor, 2011a: “Art. 1"”, en Jaime Couso y Héctor Hernández (directores), Código Penal comentado. Parte General, Santiago: Legal Publishing, pp. 7-105.

Hernández, Héctor, 2011 b: “Art. 15””, en Jaime Couso y Héctor Hernández (directores), Código Penal comentado. Parte General, Santiago: Legal Publishing, pp. 382-413.

Hernández, Héctor, 2008: "Apuntes sobre la responsabilidad penal (imprudente) de los directivos de empresa”, Revista de Estudios de la Justicia, No 10.

KASPAR, Johannes, 2017: “§ 26 StGB”, en Werner Leitner y Henning Rosenau (editores), Wirtschafts- und Steuerstrafrecht, Baden-Baden: Nomos, pp. 1126-1128.

Kloepfer, Michael y Vierhaus, Hans-Peter, 1995: Umweltstrafrecht, Múnich: C.H. Beck.

KRÄMER, Katharina, 2015: Individuelle und kollektive Zurechnung im Strafrecht, Tubinga: Mohr Siebeck. 
Kreuzberg, Bastian, 2019: Täterschaft und Teilnabme als Handlungsunrechtstypen, Berlín: Duncker\&Humblot.

KuHlen, Lothar, 1994: Umweltstrafrecht in Deutschland und Österreich, Linz: Institut für Kommunalwissenschaften und Umweltschutz.

MAnsdörfer, Marco, 2011: Zur Theorie des Wirtschaftsstrafrechts, Heidelberg: C.F. Müller.

MAtus, Jean Pierre, 2017: "El aspecto objetivo de la responsabilidad penal de los directivos principales por delitos tributarios, según la legislación chilena”, Revista de Derecho Universidad Católica del Norte, volumen XXIV, N ${ }^{\circ}$ 2. Disponible en https://scielo.conicyt.cl/scielo. php?script $=$ sci_abstract\&pid $=$ S0718-97532017000200291\&lng $=$ pt\&nrm $=$ iso $[$ Fecha de consulta: 1.04.2020].

Matus, Jean Pierre, 2013: "Sobre el sentido y alcance del artículo 291 del Código Penal”, Revista de Derecho (Valdivia), volumen XXVI, No 2. Disponible en https://scielo.conicyt.cl/scielo. php? script $=$ sci_abstract\&pid $=$ S0718-09502013000200006\&lng $=$ es\&nrm $=$ iso $[$ Fecha de consulta: 1.04.2020].

Matus, Jean Pierre y Ramírez, María Cecilia, 2019: Manual de Derecho penal chileno. Parte General, Valencia: Tirant lo Blanch.

Matus, Jean Pierre et al., 2019: "Acerca de la necesidad de una reforma urgente de los delitos de contaminación en Chile, a la luz de la evolución legislativa del siglo XXI”, en Jean Pierre Matus (director), Derecho penal del medioambiente chileno, Valencia: Tirant lo Blanch, pp. 347-399.

MuÑoz, Francisco et al., 2015: Manual de Derecho penal medioambiental (2a edición), Valencia: Tirant lo Blanch.

Muñoz, José y Fernández, José Ángel, 2010: “Estudio dogmático penal de los artículos 291 del Código Penal y 136 de la Ley General de Pesca y Acuicultura. A propósito del caso del Santuario de la Naturaleza Carlos Anwandter", Política Criminal, volumen V, No 10. Disponible en https://scielo.conicyt.cl/scielo.php?script=sci_abstract\&pid=S0718$33992010000200004 \& \operatorname{lng}=$ es\&nrm $=$ iso [Fecha de consulta: 1.04.2020].

Murmann, Uwe, 2017: Grundkurs Strafrecht (4ª edición), Múnich: C.H. Beck.

PIÑA, Juan Ignacio y Cox, Francisco, 2013: "Consideraciones sobre la vigencia del principio de confianza en la imputación en el seno de la empresa”, en Jesus-María Silva y Fernando Miró (directores), La teoría del delito en la práctica penal económica, Madrid: La Ley, pp. 183-213.

Politoff, Sergio et al., 2004: Lecciones de Derecho penal chileno. Parte General (2a edición), Santiago: Editorial Jurídica de Chile.

Roxin, Claus, 2003: Strafrecht. Allgemeiner Teil. Band II, Múnich: C.H. Beck.

Roxin, Claus, 1963: "Straftaten im Rahmen organisatorischer Machtapparate", Goltda-mmer's Archiv. RudolPHI, Hans-Joachim, 1987: "Strafrechtliche Verantwortlichkeit der Bediensteten von Betrieben für Gewässerverunreinigungen und ihre Begrenzung durch den Einleitungsbescheid”, en Winfried Küper (editor), Festschrift für Karl Lackner, Berlín: Walter de Gruyter, pp. 863-887.

SALIGER, Frank, 2012: Umweltstrafrecht, Múnich: Vahlen.

SCHAll, Hero, 1996: "Probleme der Zurechnung von Umweltdelikten in Betrieben", en Bernd Schünemann (editor), Deutsche Wiedervereinigung. Band III, Colonia: Carl Heymanns, pp. 99-128.

SCHILD, Wolfgang, 2017: “§ 25 Täterschaft”, en Urs Kindhäuser (editor), Nomos Kommentar.

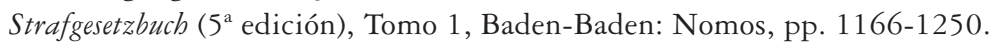

Scнмiтz, Roland, 2019: "Vorbemerkung zu § 324”, en Wolfgang Joecks y Klaus Miebach (editores), Münchener Kommentar zum Strafgesetzbuch ( $3^{a}$ edición), Tomo 6, Múnich: C.H. Beck. Disponible en http://beck-online.beck.de/Home [Fecha de consulta: 20.04.2020].

WeIss, Holger, 2008: Die rechtliche Gewährleistung der Produktsicherheit, Baden-Baden: Nomos. Wessels, Johannes et al., 2019: Strafrecht. Allgemeiner Teil (49ª edición), Heidelberg: C.F. Müller. 
Normas jurídicas citadas

Código Procesal Penal.

Código Penal chileno.

Código Penal español.

Código Penal alemán.

LEY De Bosques, publicada el 31 de julio de 1931.

Ley General de Pesca y Acuicultura, publicada el 22 de noviembre de 1989.

LEY $\mathrm{N}^{\circ} 20.393$, publicada el 2 de diciembre de 2009.

LEY N $\mathrm{N}^{\circ} 20.920$, publicada el 1 de junio de 2016.

LEY No 20.962, publicada el 16 de noviembre de 2016.

\section{Jurisprudencia citada}

BUNDESGERICHTSHOF, sentencia de 6 de julio de 1990 (BGHSt 37, 106).

Tribunal Supremo español, sentencia de 3 de julio de 1992 (Rep. La Ley N ${ }^{\circ}$ 12.612)

BUNDESGERICHTSHOF, sentencia de 11 de diciembre de 1997 (NJW 98, 767).

BUNDESGERICHTSHOF, sentencia de 26 de agosto de 2003 (BGHSt 48, 331).

BUNDESGERICHTSHOF, sentencia de 13 de mayo de 2004 (BGHSt 49, 147). 
